\title{
Función de los elementos épicos en la Carta de Lope de Aguirre (1578) y en las peticiones jurídico-administrativas del siglo XVI
}

Function of the Epic Elements in the Letter of Lope de Aguirre (1578) and in the LegalAdministrative Requests of the 16 th Century

Ofelia Huamanchumo de la Cuba

Institut für Romanische Philologie-Spanisch Sprachpraxis Ludwig-Maximilians-Universität München

München, Bayern. Deutschland

ofelia.huamanchumo@romanistik.uni-muenchen.de

Orcid ID 0000-0002-6874-4861

Resumen: El objetivo de este artículo es revisar los elementos épicos (héroes, prodigios, peripecias) de la "Carta que Lope de Aguirre escribió a Felipe II" en El Marañón (1578) de Diego de Aguilar y Córdova, relacionándolos de manera comparativa con los de las peticiones de índole jurídico-administrativo del siglo XVI, para esclarecer su función en la construcción de ambos discursos, historiográfico y jurídico: dotar de carácter extraordinario a los hechos narrados, sin perder verosimilitud. Todo ello para lograr objetivos concretos: quejarse, pedir lo justo y recibir recompensa.

Palabras clave: Elementos épicos. Género epistolar. Discurso jurídico. Lope de Aguirre. Peticiones siglo XVI.
Abstract: The objective of this article is to review the epic elements (heroes, prodigies, adventures) of the "Letter that Lope de Aguirre wrote to Felipe II" in El Marañon (1578) by Diego de Aguilar y Cordova, relating this in a comparative way with those of the legal-administrative requests of the 16 th Century to clarify their role in the construction of both historiographic and legal discourses: to endow the narrated facts with extraordinary character, without losing credibility. All that in order to achieve concrete objectives: to complain, to ask what is fair, and to receive reward.

Keywords: Epic Elements. Epistolary Genre. Legal Discourse. Lope de Aguirre. Petitions 16th Century. 


\section{INTRODUCCIÓN}

— n la formación de la literatura en español en el Nuevo Mundo el discurso épico jugó un rol decisivo, pues se ocupó de narrar de manera especial los acontecimientos históricos inmediatos, que serán referidos en verso y en prosa. Según Marrero-Fente (121-24), las características del texto épico americano se derivaron de una literatura épica renovada en la España del siglo XIV, heredera de la medieval y de las obras clásicas y sus traducciones, y manifestada sobre todo en crónicas particulares, rimadas en coplas de arte mayor, que mantenían cercanía con sus referentes históricos. En la producción épica del Nuevo Mundo la imitación y transformación de las normas épicas a la nueva realidad ocurrió cuando el modelo historiográfico en verso estaba agonizando y no había una limitación teórica que redujera la verdad a la historia y el verso a la poesía. Visto así, puede decirse que proliferarán, por ello, las crónicas, género a caballo entre la literatura y la historiografía, por ser narraciones en buena prosa que cultivaron la veracidad histórica y lo verosímil de la literatura, y donde los acontecimientos referidos podían además mantener un carácter épico, es decir, siguiendo a Valles, podían responder a los ideales heroicos o imperiales de las naciones modernas al intentar legitimar sus hazañas guerreras (36).

Para el caso de la producción narrativa en el Perú del siglo XVI, hubo una amplia variedad de clases de textos, en los que se relatan acontecimientos a la manera de una crónica épica. Ese fue el caso -tanto en documentos de carácter jurídico como en textos historiográficos- de un género en particular que practicó la narración del pasado en el interior del discurso: el género epistolar. Aquí, no obstante, será materia específica de análisis un tipo de carta: aquella cuyo objetivo fue hacer una petición oficial, puesto que en esas cartas de carácter petitorio se echó mano de elementos épicos de manera sistemática, como se mostrará en este trabajo.

\section{LA ÉPICA Y SUS PRINCIPALES ELEMENTOS}

Lo épico es una categoría estética, transtextual y común a todas las artes por su dinamismo y posibilidad del héroe de modificar el mundo, su expansión grandiosa, su exaltación del héroe como hombre individualizado y su seguridad o certidumbre interior; pero la épica, entendida como género épiconarrativo, se halla determinada por la presencia de un narrador y una historia verbalmente referida, por ser una modalidad relatora (Valles 38), donde, 
por ejemplo, la historia contada de las epopeyas, su género mayor, presenta ciertas características: un héroe guerrero, superior al resto, acompañado de fuerzas sobrenaturales, divinas o religiosas; acciones bélicas de un héroe, con peripecias, anagnórisis y desgracias; un mundo simbólico, real o mítico, cercano o remoto, presentado como realidad inamovible; presencia del viaje entre lugares geográficos; y recuperación y reactualización del pasado histórico previo (44-46). Dichas características se verán reflejadas también en las cartas indianas con peticiones oficiales, cuando se insertaban historias de tono épico para sostener una argumentación petitoria en documentos jurídicos.

Importante es notar que la épica hispánica del Quinientos se sustentaba en la superioridad moral y ontológica de lo verdadero sobre lo fingido, y se fundó en una idea humanista de la historia, que no solo la concebía como un relato de hechos verdaderos, o como memoria gestarum, sino como fuente de experiencia y moralidad, como compendio de sabiduría política, como suma de exempla, consilia y sententiae (Vega 109); por otro lado, eran rasgos de la épica aquella celebración que exaltaba las virtudes guerreras, el heroísmo en campaña y la lealtad al rey o a la patria; fruto todo ello de la reunión de las armas y las letras, que presentaban la escritura como un acto de servicio que prolonga o sustituye el servicio en campaña (116).

\section{UN TIPO DE GÉNERO EPISTOLAR: LA CARTA INDIANA}

En la tradición clásica existió el género epistolar como una clase textual que en su esencia representaba la comunicación entre un remitente y un destinatario como receptor único, distanciado en tiempo y espacio. Hubo cuatro tipos esenciales: a) la carta-mensaje (con legados); b) la carta-intercambio entre amigos; c) la carta tratado (exposición doctrinal); y d) la epístola-proemio (Castillo 437). Convivieron con ellas la carta administrativa y la carta didáctica; por ejemplo, las antologías epistolares de autores latinos, como Cicerón, Ovidio u Horacio (Ad Atticum, Epistula ad Pisones, Epistula ex Ponto); o las apostólicas de la Biblia; mientras que en el Renacimiento se cultivaron las cartas en forma de diálogos ficticios con personajes reales ya fallecidos o figuras mitológicas, e incluso se cultivará la carta en verso (Spang 239-40). Lo cierto es que la epístola renacentista será un género que pretenderá emular los epistolarios latinos y griegos, rechazando la concepción medieval de la carta. Así, los primeros tratados humanistas utilizaron el estilo humilde frente al estilo alto ca- 
racterístico del ars dictaminis del medioevo, retomando la concepción grecolatina del género (Soriano 260-61).

Esas tendencias de la carta de la temprana edad moderna pasarán a América como parte del saber europeo en los escritos de los autores españoles que ya residían en el Nuevo Mundo, para documentos reales, notariales y privados. En el presente estudio el análisis se centra en un tipo de carta que apareció dentro de textos historiográficos, como las Crónicas de América, y que se puede llamar aquí "carta indiana". Dicho término alude en general no solo a cartas privadas, sino a documentos jurídico-administrativos que desde el punto de vista diplomático sirvieron "como medio de información o vía de remisión de documentos entre la autoridad soberana y las autoridades delegadas u viceversa, o del particular a la autoridad constituida o entre particulares" (Heredia 139). El tipo más común fue la 'carta de petición', que no fue llamada así en esa época, pero que existía en la conciencia lingüística de los escribanos como clase textual jurídico-administrativa (Huamanchumo 71).

En el Manual de Torquemada ya aparece clasificada un tipo de carta que va en esa dirección, que él llama 'carta de fauor', donde será decisivo "tener respeto a la causa por que se dan, y también a la que ay para pedirlas, si es justa o ynjusta, si es buena obra si es contra razón, si es dificultosa o es hazedera, porque por vnos términos se ha de pedir lo vno, y por otros lo otro". En general, Torquemada (1574) recomienda sin embargo: "avremos de andar con el vso, y obedecerle como si fuese ley, y si por ventura halláredes otras cortesías diferentes destas, tened entendido que la diferencia será poca, y que vendrán a tener la mesma sustancia" (Zamora/C. de Zamora 250).

\section{La carta de petición en el sistema jurídico-administrativo del Perú del siglo ХИI}

En el Perú del siglo XVI, luego de concluidas las guerras civiles, los conquistadores se dieron a la tarea de reclamar los gastos que la Corona les debía reponer por los costos asumidos en las batallas sufridas durante el descubrimiento de lugares, conquista de nativos y más tarde por la pacificación del virreinato del Perú y su evangelización. En España el derecho de petición era reconocido por el rey a sus súbditos, por lo que, en el Virreinato del Perú, las autoridades coloniales también legitimaron e impulsaron estas apelaciones judiciales, por medio de la dación de leyes y ordenanzas, para todo aquel que quisiera hacer alguna petición de recompensas por servicios prestados. Los primeros conquistadores se sintieron con especial derecho a reclamar prioridad en la 
distribución de las riquezas del Virreinato, debido a que se iniciaba un proceso paralelo con la llegada de españoles advenedizos. ${ }^{1}$ Es así como surgirá una avalancha de peticiones ante la Audiencia. Esa clase textual jurídico-administrativa comprendía una epístola de carácter oficial en la que un emisor particular y privado, o su representante legal, se dirigía a la autoridad jurídico-administrativa para solicitar un pedido con argumentos que se podían comprobar con documentos probatorios anexos (Huamanchumo 71-72). Dichas peticiones eran compuestas dentro de parámetros formularios propios del lenguaje jurídico, así como de elementos retóricos según la competencia textual y discursiva del emisor, que solía estar en manos de un escribano, quien podía recurrir a tópicos del lenguaje jurídico mismo de la época, o incluso a tradiciones textuales literarias o historiográficas.

Los tipos de reclamos que impulsaban al afectado a emitir dichas cartas de petición fueron en su mayoría tres: (1) pedidos de recompensa por servicios prestados como soldados en batallas, rebeliones, conquistas, pacificaciones, a favor de la Corona; (2) pedidos de pagos de retribución por cosas dadas, prestadas o robadas durante las guerras civiles en favor de la Corona; y (3) pedidos por encontrarse en estado de pobreza y necesidad (Huamanchumo 32-36).

\section{Tópicos argumentativos y elementos épicos en torno al héroe}

Atendiendo al discurso argumentativo, se pueden encontrar diferentes tópicos retóricos en este tipo de cartas, como el de humilitas o el de originalidad, usual en los Prólogos y otros paratextos a obras literarias o historiográficas de la época (Berkenbush). Ello tiene un motivo y es que las cartas mantenían una función similar a lo que se podría decir tenía también un paratexto (Carta al Lector, Proemio, etc.) de una obra historiográfica, puesto que estas cartas antecedían a documentos probatorios de cientos de folios. En cuanto al discurso, estas cartas de petición mantenían además un estilo conciso, cuando eran redactadas por un escribano, y se extendían cuando el que la escribía era un encomendero semiculto; ${ }^{2}$ en el discurso se usaban pocos conectores copulativos, se evitaban los co-

1. Estos fueron aquellos peninsulares que, sin haber participado en ninguna etapa del descubrimiento, conquista, población, aplacamiento de rebeldes o evangelización de indios en tierras americanas, se hacían con puestos públicos y encomiendas en el Perú gracias a contactos personales o méritos de otro orden hechos en España o en Nueva España.

2. En términos de Oesterreicher, los semicultos fueron los escritores sencillos e inexpertos que tomaron por sí mismos la pluma en América. Ejemplos de semicultos se encuentran en el estudio sobre conquistadores y soldados en el rol de historiógrafos de Eva Stoll. 
nectores opositivos ("pero, mas") y se recurría con frecuencia al concesivo "aunque"; todo ello con el fin de reforzar la argumentación a favor de lo que se pedía, sin incurrir en contradicciones y apelando a la benevolencia del receptor.

En la argumentación del cuerpo de la carta se hacía referencia a factores históricos contemporáneos que se convirtieron en tópicos temáticos y eran casi indispensables en la carta de petición, por ello, su referencia contribuyó a oficializar poco a poco episodios históricos puntuales y legitimar un statu quo socioeconómico y moral de los actores implicados. Dichas referencias históricas en la bistoire de lo contado en las cartas perfilaban y resaltaban, en ese sentido, al héroe de la historia, el emisor, para otorgarle el carácter épico de ser ejemplar. Esos rasgos eran propios de las formas de escritura de la épica y la milicia, es decir, de soldados y capitanes en memoriales, crónicas, tratados, relación de hechos verdaderos, diálogos y manuales de arte militar (Vega 115).

El héroe tenía ciertas características:

a) ser fiel al Rey,

b) poseer la condición de cristiano fiel y devoto,

c) encontrarse en situación de pobreza, habiendo sido hidalgo:

yo e contraydo muchas deudas y al presente me hallo en hedad para no poder buscar y adquirir con que pasallas ny sustentarme. (1562 Aguilar)

estar yo tan pobre y necesitado como estoy. (1569 Angulo)

en ninguna manera se puede sustentar por estar muy pobre y cargado de hijas [...] teniendo considerącion a lo dicho y a que esta manco y tullido y biejo y cargado de hijos. (1571 Artiaga)

que teniendo atencion a lo dicho, y a los muchos y señalados servicios del dicho mi padre, abuelo, bisabuelo, y mios, y para mejor pueda continuarlos y que tengo quatro hijos y soy cauallero y estoy pobre. (1573 Agüero)

d) haber quedado tullido, manco, tuerto, o cojo; el ejemplo idealizado del tópico de pérdida de la mano en combate se encuentra en el Prólogo (15901612) a las Novelas ejemplares de Cervantes, cuando se describe al autor:

Perdió en la batalla naval de Lepanto la mano izquierda, de un arcabuzazo; herida que, aunque parece fea, él la tiene por hermosa, por haberla cobrado en la más memorable y alta ocasión que vieron los pasados siglos ni esperan ver los venideros, militando debajo de las vencedoras banderas del hijo del rayo de la guerra, Carlos v, de felice memoria (430-31). 
Por el contrario, un ejemplo desvirtuado de ese tópico es el que ofrece el semiculto Alonso Borregán, al presentar en dos oportunidades en sus peticiones de mercedes el argumento de haber sido asaltado por unos negros fugitivos que lo mancaron "del dedo grande de la mano derecha andando peleando con ellos por espacio de seis horas” (Stoll/Vázquez Núñez 103) y justifica con ello el hecho de hacer sus peticiones por haber "sufrido rrobo y daño y manquera de la mano derecha" (103). Por otro lado, cuando el conquistador Diego de Almagro participó en enfrentamientos contra los aborígenes de Pueblo Quemado, en 1525, perdió un ojo por herida de flecha -por lo que fue apodado el 'tuerto'- y fue rescatado de caer en prisión de los indios por Juan Roldán, quien más tarde haría lucir por ello un ojo entre las figuras emblemáticas de su Escudo de Armas (Ballesteros 21). También el soldado Alonso Borregán recurre al tópico de pérdida del ojo en sus peticiones al intentar resaltar como virtud su "sauia prudencia" de, habiendo sufrido de pronto una repentina ceguera, devolver un caballo que le obsequiara un rebelde, explicando que aquello fue un "misterio que alli aconteçio con aquellos traydores" en el pueblo de Guadacheri, donde "diome tan grande enfermedad de la cabeça que se me çego este ojo con esa nube" (Stoll/Vázquez Núñez 185). Por último, este tópico seguirá apareciendo del mismo modo incluso en la literatura eclesiástica, en uno de los paratextos introductorios al Segundo Tomo de los Sermones de Francisco de Ávila (1648), el que escribe, capellán don Florián Sarmiento, cuenta:

Antonio Sarmiento, Reuisabuelo de v. m. no fue menos valeroso heroe, llamaronle el tuerto por auerle sacado los Moros vn ojo, como Alexandro Magno los Persas, y aunque perdió la vista, no el valor, pues con gran demostracion del acabó de arrancar el ojo con sus manos; porque no le fuesse de estoruo en la pelea en que perseueró constante hasta salir con la victoria. (fol. 4r)

En las cartas jurídico-administrativas se encuentran numerosos ejemplos:

estando sobre la cibdad de guayaquil en la guerra que hubo con los naturales sobre la fundaçion della perdi la mano derecha y ansi si no he podido despues siempre he serbido en todo lo que se a ofrecido y me fue mandado como consta por la provança que tengo presentada [...] [por] aver perdido la dicha mano derecha en servicio de vuestra alteza me haga merced de gratificarme. (1561 Lopez)

en todo este tiempo a seruido en las ocasiones que se an ofreçido a su costa especialmente en las alteraçiones que huuo contra giron al seruiçio en 
que se señaló y abantajó mucho en vuestro seruiçio por lo qual los tiranos le dieron muy crueles tormentos y quedo tullido y manco de los braços. (1571 Artiaga)

e) haber participado en batallas del pasado reciente (abundan las referencias puntuales a las luchas contra los rebeldes Francisco Hernández Girón y Gonzalo Pizarro; también a la conquista de nuevos territorios):

yo serui a Vuestra alteza en sus reynos del peru onze años con mis armas y cauallo como cauallero hijodalgo que soy y me halle especialmente en su seruiçio contra gonçalo picarro y contra francisco hernandez giron que como tiranos se leuantaron en aquellos reynos contra Vuestra alteza y sus ministros. (1548 Orozco)

serui quando en el cuzco el dicho francisco hernandez se quiso alçar la primera vez. (1558 Maldonado)

an sienpre ayudado los indios de aquel balle con todos los mantenimientos y cosas necesarias para las guerras contra francisco hernandez giron y otros que se rrevelaron contra vuestro rreal seruicio en aquellas partes. (1560 Felipe)

me alle con el adelantado andagoya en el descubrimiento conquista y pacificaçión de las provinçias de la buena ventura e gobernaçion de popayan [...] con lo qual me halle devaxo del estandarte real en la vatalla que en pucara se dio al dicho francisco hernandez giron. (1563 Hernandez)

f) haber resistido muchas peripecias:

contra los tiranos y demas seruidores de vuestra corona real hasta que el dicho blasco nunez y todo su exercito fue desbaratado en el qual reenquentro yo fui preso y maltratado de los tiranos y donde a pocos dias me escape dellos y por mas seruir a vuestra magestat fuy desde la ciudad de quito hasta cartagena que ay mas de quinientas leguas de montana y tierra yerma con proposyto de benyr a estas partes a dar aviso a vuestra magestat del desbaratamiento que avia avido con la persona que antes topase que fuese con poderes de vuestra magestat el qual viaje tomo posecion todos los puertos tomados para gonçalo piçarro y como tope a vuestra magestad de la gasca vuestro presidente en panama me fuy con el devajo de vuestro real estandarte y servi hasta que fue desbaratato el dicho. (1562 Aguilar) 
y aun por saluar la uida me fue forçado andar escondido año y medio por los montes [...] con lo qual me halle devaxo del estandarte real en la vatalla que en pucara se dio al dicho francisco hernandez giron de la qual fui desvaratado y preso en todo lo qual e servido a vuestra majestat con my persona armas y cavallo a mi costa y misyon como bueno y leal uasallo pasando grandes travajos y peligros de muerte syn jamas aber desservido en cosa alguna ni echo se me socorro ni gratificaçion en vuestro rreal nombre en los dichos mis servicios segun todo consta y pareçe por esta ynformaçion. (1563 Hernandez)

espeçialmente sirui a vuestra magestat en la alteraçion contra francisco herrnandez giron y sus secuaçes hasta que ffue desbaratado y presso y hecho justiçia del y en la alteraçion de ffrancisco de silua y sus aliados que se rebelaron en la çiudad de piura y por ser yo de tanta confiança el arçobispo y los generales y audiençia real me mandaron yr al castigo y allanamiento dello y con mi yda y la gente que lleuaua ffue desbaratado el dicho tirano y se allano y hizo justiçia de los traidores. (1574 Ortiz)

g) haber sido testigo de prodigios (esto encuentra paralelos temáticos con la epopeya: exageraciones fantásticas; lucha con valentía de parte de un soldado solo, o de pocos, contra las numerosas tropas enemigas; intervención de fuerzas sobrenaturales; éxito al huir o escapar habiendo estado preso):

passe a los rreynos del peru en el qual tienpo he residido siempre en seruycio de su Magestad especialmente en esta postiera alteracion de francisco hernandez giron y sus sequaçes en la qual cuando el se alço en el cuzco me halle yo diez leguas del y alli arbole la primera vandera quen todo el reyno se alço en nombre de su Magestad y con ella vine hasta la Nasca hauiendo recogido en el camino setenta hombres y hauiendo traydo gran riesgo a causa de hauer el dicho francisco hernandez embiado tras mi cyen arcabuzeros y llegado que fui al dicho pueblo de la Nasca ques sesenta leguas de la ciudad de los Reyes e 1[a] Audiencia real $\mathrm{m}[\mathrm{e}]$ nbio vna conducta de Infanteria para que debaxo de mi vandera lleuasse aquella gente hasta la dicha çiudad de los Reyes y ansy lo puse luego por otra y entre en la dicha çiudad con la dicha gente el qual fue el primer socorro que a la Audiencia Real le entro en todo el reyno y serviçio quen todo el fue tenido en mucho y trocó mucha voluntades dañadas. (1558 Maldonado) 
la mesma noche que se alçaron en amaneçiendo / fuy el primero que nombrando la boz rreal arremeti estando solo en el abanguardia / syn ayuda de otra persona al dicho santistevan que hera el prinçipal tirano al qual es/tando armado y viniendose para mi a me matar le di una estocada por el ojo / izquierdo que le pase de parte a parte el celebro y despues acometí a todos los demas / traidores y fui en los matar prender y castigar peleando hasta que se deshizieron / según que todo consta y paresçe por esta probança de que hago presentaçión [...] y ansi mismo me halle en deshazer los / contreras en la ciudad de panama quando vinieron alli y sali herido de tres heridas / en la batalla que se les dio. (1562 Noli)

dicho diego çenteno y me prendio y robo lo que tenia que hera en mucha cantidad, de la qual dicha prision me hui y fui al asiento de potosi. (1563 Hernandez)

\section{Las cartas en la producción historiográfica indiana del siglo XVI}

Entre los estudios de historiografía indiana se puede encontrar efectivamente un tipo de cartas, considerado por los investigadores como un género en sí mismo; por ejemplo, en los escritos de Cristóbal Colón (Cartas, 1493) y en textos de Hernán Cortés (Cartas de relación, 1522), que tenían como objetivo relatar e informar de los acontecimientos sucedidos y vistos, a manera de informe para una persona o un grupo reducido de personas. Tal es el caso también de las Cartas de Pedro Sarmiento de Gamboa, diecinueve textos redactados entre 1572 y 1592, dirigidas a Felipe II, al Consejo de Indias y a los secretarios del Rey, en los que su autor quiere sacar a la luz una información, no obstante, para lanzar un pedido, un reclamo, una queja, una súplica, y finalmente casi una demanda jurídica (Benítes 18). Todas estas cartas, no obstante, no fueron redactadas para publicarse, sino para ser leídas por un grupo reducido de personas (algunos funcionarios de Audiencia, un grupo limitado de particulares, o incluso alguna autoridad, el Rey, el Virrey); al igual que en el sistema jurídico-administrativo muchas de las cartas de petición que presentaban un documento probatorio, como las Relaciones de méritos y servicios, fueron escritas solo para un determinado destinatario. ${ }^{3}$

3. Pese a ello, no faltaron textos de gran volumen, como algunas clases de documentos probatorios (Memorias, Memoriales, Relaciones) que fueron publicados en la época junto con las cartas de petición que los antecedieron, debido a que su escritura podía concebirse, en términos de Vega "como 
Otro tipo especial de cartas que se publicó entre los siglos XVI y XVII fueron las que aparecieron dentro de las Crónicas y que ya no tenían una función pragmática, a nivel jurídico, sino ficcional, a nivel historiográfico o literario. Dichas mímesis de cartas buscaban llegar al lector a través del discurso epistolar, es decir, con un lenguaje más emotivo y cercano al lector para que este se identificara e involucrara más con las cuitas y los pensamientos o sentimientos de los protagonistas. Es el caso de la Carta que Lope de Aguirre escribió a Felipe II, objeto de análisis en este estudio, que aparece dentro de la crónica $E l M a$ rañón (1578) de Diego de Aguilar y Córdoba y que confirma que dicho autor seguía la tradición de los poetas españoles del XV, que escribían épica histórica no solo para rescatar del olvido las gestas de los héroes nacionales del pasado y del presente, apostando por la veracidad de lo narrado y aludiendo a que se habían documentado o sido testigos de los hechos, sino porque buscaban en la literatura épica los mismos valores que los intelectuales en la historia, es decir, el magistra vitae, opuesto a la mera ficción caballeresca (Vilà 8-27).

\section{La carta de Lope de Aguirre al Rey don Felipe II}

Lope de Aguirre fue un soldado español, famoso por haber sido cruel, indomable y haberse rebelado a la Corona, cuya legitimidad él cuestionó de manera original. Algunos de sus biógrafos lo relacionan con los hidalgos vascongados de los siglos XVI y XVII, y por tanto, gente de letras y notarías (Matamoro 15), con lo cual sería dable reconocerle la autoría, en contenido, forma y estilo, de la carta en cuestión. Con todo, pese a los escasos datos sobre su origen, Aguirre se convirtió en figura especial de varias crónicas historiográficas de la época en torno a la búsqueda de El Dorado y a las empresas de descubrimiento en la zona del río Marañón en el Amazonas. ${ }^{4}$

un acto personal de servicio a la patria o a señores y reyes [...], a un ideal de literatura verdadera y provechosa, con utilidad pública como privada, capaz de suscitar la aspiración a la virtud" (133). Es el caso, por ejemplo, de la Relación de méritos y servicios de Nicolás de Rivera, publicada a manera de libro (AGI, Patronato, 101, r. 4), donde se puede ver con claridad el papel de 'prólogo', que asumió la carta de petición. Por otra parte, se sabe también de la Carta de Pedrarias Dávila de abril de 1525 (AGI, Patronato, 28, r. 18) con las primeras noticias sobre el descubrimiento, que fue puesta en verso, en octavas, por un italiano desconocido (Esteve Barba 442-43).

4. En la selección de crónicas de Carrillo se encuentran fragmentos de por lo menos cinco en torno a Lope de Aguirre: la crónica de Gonzalo de Zúñiga; la de Francisco Vásquez y Pedrarias de Almesto; la de Toribio de Ortiguera; una Crónica Anónima; la de Custodio Fernández; y la de Diego Aguilar y Córdoba (275-348). Por su parte, Ingrid Galster en un voluminoso estudio comparó fuentes y análisis que se habían ocupado de la figura de Aguirre en la historiografía y la ficción histórica desde 1561 hasta 1992. 
Entre el significativo número de dichas crónicas que retratan a Aguirre El Marañón (1575) de Diego de Aguilar y Córdoba es considerada la más completa, pues reunió la vida y obra del rebelde, y la famosa Carta que dirigiera al rey Felipe II, fuera de que Emiliano Jos publicara la Carta de Aguirre (1927) contrastándola con la versión de Vásquez, y de que Diego de Aguilar-como asegura Díez Torres en su análisis de El Marañón- hubiera copiado la carta recogida por el soldado Francisco Vásquez en su relación. ${ }^{5}$

También se sabe de otra fuente de dicha Carta de Lope de Aguirre: un texto fechado el 18 de setiembre de 1821 que el libertador Simón Bolívar ordenara difundir en El Correo Nacional, de Maracaibo, por considerarla el acta primera de la independencia de América, pero que no se llegó a publicar y de la cual se guardaron copias y recibos, que finalmente salieron a la luz a finales el siglo XIX (Matamoro 117). Pese a todo, este biógrafo cuestiona también la autoría de la carta:

¿Es nuestro personaje [Lope de Aguirre] el autor directo del documento? No podemos saberlo a ciencia cierta. Tal vez, en tierra firme, se unió a gente que, sin ser de la expedición marañona, tuviera noticias de manifiestos similares y anteriores habidos en España y América, desde las comunidades castellanas hasta Gonzalo Pizarro. Establecer este punto arrojaría mucha luz sobre la penumbrosa personalidad de Lope de Aguirre, ya que revela cierta fundamentación jurídico religiosa que daría elementos para perfilar al caudillo como un hijodalgo de instrucción, un hombre reflexivo a la vez que un duro soldado, un sujeto dado a la reacción inmediata y cruel pero, en su momento, a la meditación y a la distancia. (129)

Lo cierto es que Lope de Aguirre escribió una carta a Felipe II, cuyo registro original no se guarda, sino en fuentes secundarias o indirectas. Dichas fuentes, como las dos mencionadas, aún cuando fuesen meras variantes de una carta original, se convierten en recreaciones que no dejan de transmitir una verdad ficcional.

5. Díez Torres, editor crítico de El Marañón, ha investigado que Aguirre hizo llegar su famosa misiva a la Real Audiencia de Santo Domingo a través de un cura, al que previamente había secuestrado en la Isla Margarita. También afirma que no se conoce la versión original de la carta, de la cual existen numerosas copias conservadas que fueron incluidas en los procesos judiciales y en las crónicas sobre los marañones, las cuales no presentan gran variedad, pero que, pese a ello, podría esperarse un cotejo de estas y un estudio de los posibles copistas (205). 
Sobre la fuente El Marañón (1578) y su autor

Sobre Diego de Aguilar y Córdoba se tienen escasos datos biográficos. En la Historiografía Indiana de Esteve Barba es presentado como andaluz descendiente de los Guadalcázar, que pasó a las Indias y ocupó varios cargos públicos en instituciones de la Corona y participó en la Academia Antártica; Barba señala a Rafael de la Fuente Benavides, José Toribio Medina y Guillermo Lohmann Villena como sus principales biógrafos y destaca de manera especial las facultades literarias de Diego de Aguilar y Córdoba, poeta elogiado por Cervantes, autor de sonetos, pero también de una sobria prosa de relevancia historiográfica y de gran aporte a la historia de la literatura, pues da razón de varios de los versificadores más antiguos del Virreinato peruano (414-16). De otra parte, Delgado, en su breve compendio de Literatura Colonial (16), presenta a Aguilar y Córdoba diferenciado sustancialmente de otros cronistas cuyas obras tuvieron más un carácter histórico y que fueron solo en raras ocasiones contadas con galas literarias y valores estéticos; por lo que Aguilar y Córdoba pertenecería así a los primeros cultivadores de lo que podría llamarse etapa del estilo renacentista en la literatura colonial.

Tanto Esteve Barba como Delgado coinciden en señalar el valor literario de la crónica El Marañón (1578) -con su homónima en verso con el mismo tema y título- sobre la cruenta expedición selvática de Lope de Aguirre, y una de cuyas copias fue encontrada por el padre Rubén Vargas Ugarte en el Museo Británico: ${ }^{6}$

Está escrita en una sólida y equilibrada prosa renacentista por su materia, posee un sugestivo aire novelesco que permite leerla con facilidad y agrado; por último, en los preliminares, dedicatorias y poemas encomiásticos con que se inicia la obra, según los usos de esos tiempos, hay noticias de varios poetas de entonces, pertenecientes a la llamada Academia Antártica e iniciadores de la literatura culta en el Perú. Nada se sabe del poema de Aguilar, si lo hubo, aunque Menéndez y Pelayo afirmara haberlo visto. Aguilar escribió también un libro de diálogos en prosa, La soledad entretenida, hoy perdido. (Delgado 17)

6. En el estudio de Emiliano Jos, basado en documentos inéditos, se señaló también como fuente de la carta de Lope de Aguirre: "Según la copia del Manuscrito de Aguilar en el British Museum. Add. 17616. Cap. II del libro $3^{\circ}$, fols. 139r-144v" (200). 
El códice original de El Marañón (1578), autógrafo, se encuentra en la Biblioteca de la Universidad de Oviedo; consta de tres partes: la primera es una introducción; la segunda cuenta las atrocidades de Aguirre hasta llegar a la Burburata; y la tercera, desde ese punto hasta su muerte (Esteve 416). Para el análisis en el presente artículo se ha tomado el texto de la carta de Lope de Aguirre de la edición de Emiliano Jos, donde aparece con el título: "Carta que Lope de Aguirre escribió a Felipe II" (196-200), basada en una copia del Manuscrito de Aguilar y con acotaciones a pie de página de variantes del cronista Vásquez.

\section{ANÁLISIS COMPARATIVO}

A continuación, se expondrán los elementos comunes en torno a la figura del héroe, núcleo de la narración épica, de manera comparativa entre las peticiones y el texto de la Carta de Lope de Aguirre.

Muy acertadamente y siguiendo las tradiciones textuales de las cartas de petición, ya en el primer párrafo de la Carta el emisor se presenta siguiendo el perfil de quien apela judicialmente, es decir, con el perfil del héroe conquistador que mantiene las siguientes características: [a] fidelidad al Rey; [b] condición de cristiano; $[c]$ con antepasados hidalgos, pero empobrecido y deshonrado. Del mismo modo, cumple con informar antes que nada sobre los motivos que lo mueven a escribir al Rey: [1] pedir recompensa por servicios prestados como soldado en batallas, descubrimientos y conquistas; [2] dejar en claro que ha prestado bienes a la Corona, por los que le corresponderían pagos en retribución:

Rey Felipe, natural español hijo de Carlos invencible:

Lope de Aguirre, [a] $]^{7}$ tu mínimo vasallo, [b] cristiano viejo, [c] de medianos padres y en mi prosperidad hijodalgo, natural vascongado, en el reino de España, en la villa de Oñate vecino.

En mi mocedad pasé el oceano a las partes del Piru [1] por valer mas con la lanza en la mano y por cumplir con la deuda que debe todo hombre de bien, assí mismo en veinte y cuatro años te he hecho muchos servicios en el Piru en conquistas de indios y en poblar pueblos en tu servicio, especialmente en batallas y recuentros que ha habido

7. En las citas de esta sección las negritas son mías, donde letras y números en corchetes corresponden a las características dadas. 
en tu nombre, siempre conforme a mis fuerzas y posibilidad, sin importunar a tus oficiales por paga [2] ni socorro, como parescerá por tus reales libros.

Creo bien, [excelentísimo] Rey y señor, aunque para mi y mis compañeros no has sido tal, sino cruel e ingrato, y tambien creo que te deben de engañar, los que te escriben desta tierra, como estan lejos. (Jos 196)

Seguidamente, el emisor utiliza un argumento poco usual en las cartas de petición jurídicas: dar cuenta de los malos funcionarios de la administración colonial; circunstancia que no aporta sublimidad a la figura del héroe, pero que justifica en parte su rebeldía y su condición de empobrecido:

Acúsote Rey que cumple haya toda justicia y rectitud para tan buenos vasallos como en estas tierras tienes, aunque yo por no poder sufrir mas la crueldades que usan estos tus Oidores, Visorrey y gobernadores, he salido de hecho con mis compañeros, cuyos nombres después te diré, de tu obediencia y desnaturalizandonos de nuestra tierra que es España, para hacerte la mas cruel guerra que nuestras fuerzas pudieren sustentar y sufrir; y esto, cree rey y señor, nos ha hecho hacer el no poder sufrir los grandes pechos, premios y castigos injustos, que nos dan tus ministros, que por remediar a sus hijos y criados [c] han usurpado y robado nuestra fama, vida y honra, que es lástima Rey el mal tratamiento que se nos ha hecho. (196-97)

No podía faltar una característica física del héroe de guerra en el discurso de las peticiones: [d] el haber perdido una parte del cuerpo en batalla; pero no en cualquiera, sino [e] en las más resaltantes de los acontecimientos contemporáneos, por ejemplo, en la rebelión de Hernández Girón:

Estoy cojo de una pierna derecha de dos arcabuzazos que me dieron en el valle de Chuquinga con el mariscal Alonso de Alvarado, siguiendo tu voz y apellido [e] contra Francisco Hernández Girón, rebelde a tu servicio como yo y mis compañeros al presente somos y seremos hasta la muerte, [...], ellos te dieron la victoria, porque si no se pasaran, hoy fuera [e] Francisco Hernandez rey del Piru. (197)

Y no porque yo [d] como hombre lastimado y manco de mis miembros en tu servicio, y mis compañeros viejos y cansados en lo mismo, te he de dejar de avisar que nunca fíes en estos letrados tu real conciencia, que no cumple a tu real servicio descuidarte con estos que se les va todo 
el tiempo en casar hijos e hijas, y no entienden en otra cosa, y su refran entre ellos muy común es: [d] "A tuerto o a derecho nuestra casa hasta el techo". (198)

¡Ay, ay, que lástima tan grande que Cesar y Emperador tu padre, conquistase con las fuerzas de España la superba Germania y gastase tanta moneda llevada destas Indias descubiertas por nosotros, [c] que no te duelas de nuestra vejez y cansancio siquiera para matarnos la hambre un día! (198-99)

En la Carta el emisor vuelve varias veces sobre [b] los asuntos cristianos: hace mención de personajes de las historias bíblicas, o de la historia de la Iglesia (Lucifer, Nabucodonosor, Lutero) y a su propia condición de cristiano:

Cierto, [b] a Dios hago solemne voto yo y mis doscientos arcabuceros marañones, conquistadores, hijosdalgo, de no te dejar ministro tuyo a vida, porque ya sé hasta dónde alcanza tu clemencia; y el día de hoy nos hallamos los mas bien aventurados de los nascidos por estar en estas partes de Indias [b] teniendo la fee $\mathbf{y}$ mandamientos de Dios enteros y sin corrupción como cristianos, manteniendo todo lo que predica la santa madre iglesia de Roma, y pretendemos, aunque pecadores en la vida, rescibir martirio por los mandamientos de Dios. (197)

A la salida que hicimos del río de las Amazonas que se llama el Marañón, en una isla poblada de cristianos que tiene por nombre la Margarita, vi [b] unas relaciones que venían de España de la gran cisma de luteranos que hay en ella que nos pusieron temor y espanto, y en nuestra compañía hubo un aleman llamado Monteverde y le hice hacer pedazos. Los hados darán la paga a los cuerpos, pero donde nosotros estuvieremos cree, excelente Príncipe, que cumple que todos vivan muy [b] perfectamente en la fe de Cristo. (197-98)

[b] En fe de cristianos te juro, rey y señor, que si no pones remedio en las maldades desta tierra, que te ha de venir castigo del cielo. Y esto digolo por avisarte de la verdad, aunque yo y mis compañeros no esperamos ni queremos de ti misericordia. (198)

Anden las guerras por donde anduvieren pues para los hombres se hicieron; mas en ningun tiempo ni por adversidad que nos venga, [b] no dejaremos de ser sujetos a los preceptos de la Santa Madre Iglesia romana. (199) 
mas por nuestros pecados quieren que doquiera que los topemos nos inquemos de rodillas y los adoremos [b] como a Nabucodonosor, cosa, cierto, insufrible. (198)

No obstante, el emisor es también capaz de criticar a la Iglesia, tema que contrasta sustancialmente con los de las cartas de petición, donde no se menciona:

La disolución de los frailes es tan grande en estas partes, que yo entiendo, que conviene que venga sobre ellos tu ira y castigo, porque ya no hay ninguno que presuma de menos que de gobernador. Mira, mira Rey, que no creas lo que te dijeren, pues las lagrimas que allá echan delante tu real persona, es para venir acá a mandar. Si quieres saber la vida que por acá tienen es entender en mercaderías, procurar y adquirir bienes temporales, vender los Sacramentos de la Iglesia por prescio, enemigos de pobres, incaritativos, ambiciosos, glotones y soberbios, de manera que, por mínimo que sea un fraile pretende mandar y gobernar todas estas tierras. Pon remedio, rey y señor, porque destas cosas y malos ejemplos, no está imprimida ni fijada la fee en los naturales, y mas te digo, que si esta disolución de estos frailes no se quita de aquí, no faltarán escándalos. (198)

Pues los frailes a ningun indio pobre quieren enterrar y estan aposentados en los mejores repartimientos del Piru. La vida que llevan es aspera y trabajosa, porque cada uno dellos tiene por penitencia en sus cocinas una docena de mozas y no muy viejas, y otros tantos muchachos que les van a pescar, a matar perdices y a traer frutas; todo el repartimiento tiene que hacer con ellos. (198)

El emisor conoce al dedillo los procedimientos jurídicos y reconoce, desde una posición contestataria, que su carta es una petición que no necesita ceñirse a las formas de las peticiones jurídico-administrativas oficiales, por ejemplo, la de presentar testigos, o acudir a recursos probatorios. Por otro lado, vuelve también a resaltar [a] su condición de vasallo y de [2] acreedor de la Corona, así como de [1] descubridor:

Si yo y mis compañeros por la gran razon que tenemos nos habemos determinado a morir, desto, cierto, y de otras cosas pasadas, singular rey, tu has sido causa, [a] por no te doler del trabajo de tus vasallos [2] y no mirar lo mucho que les debes, porque si tu no miras por ellos y te descuidas con estos tus Oidores nunca se acertará en el gobierno. Por cierto, no hay para que presentar testigos mas de avisarte como estos tus 
Oidores tienen cada uno cuatro mil pesos de salario y ocho mil de gastos, $\mathrm{y}$ a cabo de tres años, tienen cada uno sesenta mil pesos ahorrrados y heredamientos y posesiones; y con todo esto si se contentasen con servirlos como a hombres que los servimos, medio mal y trabajo sería el nuestro. (198)

No podemos creer, excelente rey y señor, que tu seas cruel para tan buenos vasallos como en estas partes tienes, sino que estos tus malos Oidores y ministros lo deben de hacer sin tu consentimiento. Dígolo, excelente rey, porque en la ciudad de los Reyes, dos leguas della, [1] se descubrió junto a la mar una laguna donde había algún pescado, que Dios lo permitió que fuese así, y estos tus malos Oidores y oficiales de tu real persona, por aprovecharse del pescado, como lo hacen para sus regalos y vicios, lo arriendan en tu nombre dandonos a entender, como si fuésemos inhabiles, que es por tu voluntad. Si ello es así, déjanos, señor, pescar algun pescado siquiera, pues trabajamos en descubrirlo, porque el Rey de Castilla no tiene necesidad de cuatrocientos pesos que es la cantidad porque se arrienda. (199)

Después de haber expuesto los principales elementos de una carta de petición, el emisor pronuncia la primera frase petitoria directa, reforzada con [c] el tópico del empobrecido:

Y pues, esclarecido rey, no te pedimos mercedes en Córdoba, ni en Valladolid, ni en toda España que es tu patrimonio, [c] duelete, señor, de alimentar los pobres cansados en los frutos y reditos desta tierra, y mira, rey y señor, que hay Dios para todos, y igual justicia, premio, paraiso infierno. (199)

En los párrafos siguientes de la carta el emisor da rienda suelta a la exposición de [f] sus peripecias, en las que han participado [e] personajes de renombre contemporáneos:

En el año de cincuenta y nueve dio el Marqués de Cañete la jornada del río de las Amazonas a [e] Pedro de Orsua, navarro, o por mejor decir, francés, [f] y tardó en hacer navíos hasta el año sesenta en la provincia de los Motilones, que es en el Pirú, y porque los indios andan rapados a navaja se llaman Motilones. [f] Aunque estos navíos por ser la tierra donde se hicieron lluviosa, al tiempo del echarlos al agua se nos quebraron los mas dellos, hicimos balsas y dejamos los caballos 
y haciendas y nos echamos el río abajo con harto riesgo de nuestras personas.

Luego topamos los mas poderosísimos ríos del Piru, de manera que nos vimos en Golfo Dulce. Caminamos de prima faz trecientas leguas del embarcadero donde nos embarcamos la primera vez. (199)

El emisor combina también las historias de sus peripecias y cuitas de soldado con la exaltación de su crueldad, como parte de $[\mathrm{g}]$ la fuerza extraordinaria que posee para vencer a muchos soldados y escapar de la muerte, así como de los pocos esfuerzos que le toma matar a todos con una crueldad y una facilidad prodigiosas; y también vencer las dificultades geográficas más asombrosas:

Fue este mal Gobernador tan perverso y vicioso y miserable que no lo pudimos sufrir, y ansí por ser imposible sufrir sus maldades y por tenerme por parte en mi causa como me ternan, excelente rey y señor, no diré mas de que le matamos, muerte, cierto, bien breve. Y luego a un mancebo caballero de Sevilla llamado D. Fernando de Guzman, le alzamos por nuestro rey y le juramos por tal, como tu real persona verá por las firmas de todos los que en ello nos hallamos, que quedan en la isla Margarita, en estas Indias; y a mi me nombraron su maestre de campo y porque no consentí en sus insultos y maldades, [g] me quisieron matar y yo maté al nuevo rey, y al capitan de su guardia y al teniente general y a cuatro capitanes, y a su mayordomo y a su capellan clerigo de misa, y a una mujer de la liga contra mi, y a un comendador de Rodas, y a un almirante, y a dos alferez y otros seis aliados suyos, y con intencion de seguir la guerra adelante $y$ morir en ella por las muchas crueldades que tus ministros usan con nosotros, nombré de nuevo capitanes y sargento mayor, y quisieronme matar y los ahorqué a todos. (199-200)

Caminando nuestra derrota, pasando todas estas muertes y malas venturas en este río Marañon [g] tardamos hasta la boca del, que entra en la mar, mas de diez meses y medio: caminamos cien jornadas justas, anduvimos mil y quinientas leguas.

Es río grande y temeroso, tiene de boca ochenta leguas de agua dulce, tiene grandes bajos y ochocientas leguas de desierto sin genero de poblado, como tu Magestad lo vera por una relación que hemos hecho bien verdadera. En la derrota que corrimos tiene mas de seis mil islas. ¡Sabe Dios como escapamos de lago tan temeroso! 
Avisote rey y señor no proveas ni consientas que se haga alguna armada para este río tan mal afortunado, porque [b] en fee de cristiano te juro, rey y señor, que si vinieren cien mill hombres ninguno escapará, porque la relación es falsa y no hay en el río otra cosa que desesperar, especialmente para los chapetones de España. (200)

Finalmente, en el último párrafo de la carta se exponen los nombres de los participantes de la travesía de la rebelión de Lope de Aguirre, el emisor. Se dan sus nombres y apellidos, como correspondía en tiempos del humanismo europeo, y se vuelve a recalcar la condición de hidalgos de muchos de ellos. Hacia el remate de la carta se hace uso explícito de dos fórmulas jurídicas: la una, correspondiente a desearle el bien al receptor, en este caso, el Rey: "ruego a Dios te aumente en prosperidad"; la otra, "es gracia que espero alcanzar":

Los capitanes y oficiales que al presente llevo y prometen de morir en esta demanda como hombres lastimados son: Juan Jeronimo de Espínola ginovés, almirante; Juan Gómez, Cristobal García, capitan de infantería, los dos andaluces; capitán de a caballo, Diego Tirado andaluz, que tus Oidores, rey y señor, le quitaron con grande agravio indios que había ganado con su lanza; capitan de mi guardia Roberto de Socaya y a su alferez $\mathrm{Nu}-$ flo Hernandez, valenciano; Juan Lopez de Ayala de Cuenca, nuestro pagador; alferez general general Blas Gutierrez, conquistador de veinte y siete años; Juan Ponce, alferez, natural de Sevilla; Custodio Hernández, alferez, portugués; Diego de Torres, alferez, navarro; sargento Pedro Gutierrez Viso y Diego de Figueroa; Cristobal de Rivas, conquistador; Pedro de Rojas andaluz, Juan de Saucedo alferez de a caballo; Bartolomé Sanchez Paniagua, nuestro borrachel; Diego Sanchez Bilbao provehedor, García Navarro, vehedor general. Y [d] otros muchos hijosdalgo desta liga [i] ruegan a Dios, Nuestro Señor, te aumente siempre y ensalce en prosperidad contra el turco y franceses y todos los demas que en essas partes te quisieren hacer guerra, y en estas [1] nos dé Dios gracia que podamos alcanzar con nuestras armas el precio que se nos debe, pues nos han negado lo que de derecho se nos debía.

Hijo de fieles vasallos tuyos vascongados, y yo, rebelde hasta la muerte por tu ingratitud. Lope de Aguirre, el Peregrino. (200)

En la despedida de la Carta, se puede ver el contraste con la figura épica de las cartas de petición, pues el emisor subraya el carácter rebelde, y no de sumisión, con el que se ha presentado desde el comienzo, pues ya en el primer párrafo 
anunciaba: "Creo bien excelentísimo Rey y señor que para mi y mis compañeros no has sido tal, sino cruel e ingrato" (196). Ya no se trata de un vasallo fiel al Rey, sino que ha devenido en un personaje sublevado a la Corona: "rebelde hasta la muerte por tu ingratitud" (200), por lo que se podría hablar de un antihéroe en esta carta épica.

\section{Conclusiones}

Luego de la sucinta presentación del renovado carácter épico de la producción narrativa en el Nuevo Mundo, se vio que los textos narrativos del sistema jurídico-administrativo y los historiográficos del Perú del siglo XVI pudieron mantener una relación sustancial con dicho carácter épico por diversos motivos que tuvieron que ver con circunstancias históricas.

A su vez, en una segunda reducción metodológica, se vio que, dadas las características con que eran presentados los protagonistas de los hechos expuestos en las cartas de petición, estas mantenían también estrechas relaciones con otras cartas insertadas en textos de ficción, historiográfica o literaria, como las crónicas: presentar un personaje de carácter épico, es decir, un héroe.

Una vez señaladas de forma puntual las características de ese tipo de héroe y de haber procedido a la comparación de sus formas de aparición en ambos contextos textuales, las cartas de petición y la Carta de Lope de Aguirre, se pueden lanzar algunas conclusiones.

En primer lugar, se puede afirmar con certeza que la Carta de Lope de Aguirre corresponde al formato de una carta de petición a la usanza del sistema jurídico-administrativo de la época, pues sigue ciertas fórmulas de la presentación y el cierre con la petición, y repite los tópicos vistos. Ello significaría que el autor de la Carta de Lope de Aguirre tuvo que ser una persona bien instruida -lo cual a todas luces es evidente por el excelente nivel de la prosa en la Carta-, que estuvo lejos de un ser un autor semiculto; por ello, Aguilar y Córdova, el autor de la crónica El Marañón, uno de los prosistas más elegantes de los primeros años de la historia de la literatura peruana, se atrevió a insertar en medio de su narración de los acontecimientos una epístola de lenguaje elevado, presentada como la propia voz de Aguirre -a sabiendas tal vez del nivel de instrucción que, a causa de alguna especial condición social, pudiera haber tenido el soldado- en su afán de querer mostrar que había recurrido a fuentes fidedignas como todo buen autor épico. 
En segundo lugar, el uso de los elementos épicos vistos en las cartas de petición y en la Carta de Lope de Aguirre pareciera mostrar una conciencia muy clara, por parte de los escribanos y de Aguilar y Córdova, de las posibilidades funcionales de dichos elementos como instrumentos de apoyo a la argumentación, ya que su empleo en la construcción de ambos discursos, literario o jurídico, podía dotar de carácter extraordinario a los hechos narrados sin perder verosimilitud.

Por último, el texto de los documentos jurídico-administrativos tenía fines pragmáticos muy claros: exponer acciones heroicas que legitimaran las peticiones de recompensa, alimentando el remordimiento de conciencia de las autoridades con las sutiles quejas que llevaban a conceder un carácter justo a las peticiones; para ello, el escribano tenía que aplicar su mejor pluma para no caer en la exageración del relato de los acontecimientos que sustentaban su argumentación retórica. Por el contrario, el autor de El Marañón podía darse el lujo de jugar con el carácter heroico -o antiheroico- de su protagonista, Lope de Aguirre, ya no un hidalgo de carne y hueso, sino un personaje literario, a quien, para mayor desafío, Aguilar y Córdova concede el honor de entrar con propia pluma en el discurso del mismo cronista. Así, considerando los temas de las tradiciones textuales jurídicas, Aguirre aparece en su Carta como un ser anticlerical en medio de tantas referencias cristianas y como un vasallo del Rey que en la mímesis de un marco legal descarga toda su rebeldía y se declara libre, tal cual lo permite la libertad de la construcción del discurso literario, algo de lo que Aguilar y Córdova tenía conocimiento y que a su vez lo llevó a agregar la famosa Carta a su crónica.

\section{FUENTES INÉDITAS}

1548 Orozco: AGI, Patronato, 192, n. 1, r. 49.

1558 Maldonado: AGI, Patronato, 101, r. 8.

1560 Felipe: AGI, Lima, 205, n. 16.

1561 Lopez: AGI, Patronato, 104b, r. 16.

1562 Aguilar: AGI, Lima, 205, n. 17.

1562 Noli: AGI, Patronato, 150, n. 14, r. 7.

1563 Hernandez: AGI, Lima, 205, n. 21.

1569 Angulo: AGI, Lima, 206, n. 7.

1571 Artiaga: AGI, Patronato, 117, r. 3.

1573 Agüero: AGI, Patronato, 119, r. 1.

1574 Ortiz: AGI, Patronato, 120, n. 1, r. 3. 


\section{OBRAS CITADAS}

Ávila, Francisco de. Segundo tomo de los sermones de todo el año en lengua indica, y Castellana, para la enseñana de los Indios, y extirpacion de sus Idolatrias. Lima: Imprenta de Diego de Cabrera, 1648.

Ballesteros, Manuel. Diego de Almagro. Madrid: Quorum, 1987.

Benítes, María Jesús. "Las cartas de Sarmiento de Gamboa: la escritura de la súplica". Telar: Revista del Instituto Interdisciplinario de Estudios Latinoamericanos 1.1 (2004): 17-37.

Berkenbush, Gabriele. Klassiker der spanischen Spracbwissenschaft: Eine Einführung in die Sprachwissenschaft des 16. und 17. Fabrbunderts. Bonn: Romanistischer Verlag, 1990.

Carrillo, Francisco. Cronistas de las Guerras Civiles, así como del levantamiento de Manco Inca y el de don Lope de Aguirre llamado "La ira de Dios". Lima: Horizonte, 1989.

Castillo García, Carmen. "La epístola como género literario: de la antigüedad a la edad media". Estudios clásicos 18.73 (1974): 427-42.

Cervantes Saavedra, Miguel de. Obras completas, II: Galatea. Novelas Ejemplares. Persiles y Segismunda. Eds. Florencia Sevilla y Antonio Rey. Madrid: Centro de Estudios Cervantinos, 1994.

Delgado, Washington. Literatura colonial: de Amarilis a Concoloncorvo. Lima: San Marcos, 2002.

Díez Torres, Julián. "Los marañones y la polémica de la conquista: retórica e ideas políticas en la carta de Lope de Aguirre a Felipe II". Alpha 33 (2011): 201-14.

Esteve Barba, Francisco, ed. Historiografía indiana. Madrid: Gredos, 1992.

Galster, Ingrid. Aguirre o La posteridad arbitraria: la rebelión del conquistador vasco Lope de Aguirre en historiografía y ficción histórica (1561-1992). Bogotá: Universidad Javeriana, 2011.

Heredia, Antonia. Recopilación de estudios de diplomática indiana. Sevilla: Diputación Provincial de Sevilla, 1985.

Huamanchumo, Ofelia. Encomiendas y cristianización: análisis pragmático de documentos jurídicos y administrativos del Perú. Siglo XVI. Piura: UDEP, 2013.

Jos Pérez, Emiliano. "Carta de Lope de Aguirre a Felipe II". La Expedición de Ursúa al Dorado, la rebelión de Lope de Aguirre y el itinerario de los Marañones: según los documentos del Archivo de indias y varios manuscritos inéditos. Ed. Agustín Millares Carlo. Vol. 1. Huesca: Impr. V. Campo, 1927. 196200. 
Marrero-Fente, Raúl. "Épica, Historia y Verdad en La Conquista del Perú (1538)". Iberoromania 58 (2003): 120-33.

Matamoro, Blas. Lope de Aguirre. Madrid: Ediciones Quorum, 1987.

Oesterreicher, Wulf. "El español en textos escritos por semicultos: competencia escrita de impronta oral en la historiografía indiana (s. XVI)". El español de América en el siglo XVI (Actas del Simposio del Instituto Iberoamericano de Berlín, celebrado el 23 y 24 de abril de 1992). Ed. Jens Lüdtke. Biblioteca Ibero-Romania 48. Frankfurt am Main: Vervuert, 1994. 155-90.

Soriano Sancha, Guillermo. Tradición clásica en la Edad Moderna: Quintiliano y la cultura del bumanismo. Logroño: Instituto de Estudios Riojanos, 2013.

Spang, Kurt. "El género epistolar: un intento de definición genérica". Rilce 16.3 (2000): 239-56.

Stoll, Eva. Konquistadoren als Historiographen: Diskurstraditionelle und textpragmatische Aspekte in Texten von Francisco de Jerez, Diego de Trujillo, Pedro Pizarro und Alonso Borragán. Tübingen: Gunter Narr, 1997.

Stoll, Eva, y María de las Nieves Vázquez Núñez, eds. Alonso Borregán. La Conquista del Perú. Textos y Documentos Españoles y Americanos. Madrid/Frankfurt am Main: Iberoamericana/Vervuert, 2011.

Valles Calatrava, José R. Teoría de la narrativa: una perspectiva sistemática. Madrid/Frankfurt am Main: Iberoamericana/Vervuert, 2008.

Vega, María José. "Idea de la épica en la España del Quinientos". La teoría de la épica en el siglo XVI (España, Francia, Italia y Portugal). Eds. María José Vega y Lara Vilà. Madrid: Academia del Hispanismo, 2010. 103-35.

Vilà, Lara. "Fama y verdad en la épica quinientista española: el virgilianismo político y la tradición castellana del siglo XV". Studia Aurea 4 (2010): 135. 1 de febrero de 2017. <http://www.studiaaurea.com/articulo.php?id= $129>$.

Zamora, Alonso, y Josefa C. de Zamora, eds. Antonio de Torquemada. $M a-$ nual de escribientes. 1574. Madrid: Anejos del Boletín de la Real Academia Española, 1970. 